\title{
Management developed DSS and organizational transformation
}

\author{
S. A. Carlsson \\ Department of Informatics \\ Lund University, Ole Römers väg 6 \\ SE-223 63 Lund, Sweden \\ e-mail: sven.carlsson@ics.lu.se
}

\begin{abstract}
Management developed Decision Support Systems (DSS) are a major factor in business computing. Most of these DSS are developed using evolutionary approaches. These approaches stress continuous development of decision tasks. One drawback of continuous development of decision tasks is that it can lead to exploitation of old tasks instead of exploration of new possibilities. In an organization that experienced this problem, an intervention was made, using two approaches presented in this paper. As management developed DSS are becoming more important to organisations, it is critical to assess their value. For such an assessment we propose that the resource-based view of the firm might be useful.
\end{abstract}

\section{Keywords}

Decision support systems, management development, development approaches, resource-based view, organisational learning, organisational change and transformation, competitive advantage

\section{INTRODUCTION}

Management development of Decision Support Systems (DSS) is a major factor in business computing - see, for example, Brancheau and Brown's (1993) review of end-user computing research. There are several reasons, technical as well as managerial and organisational, for this phenomenon. The technical reasons, which have received most attention in the literature (Fahy and Murphy, 1996), include the DSS development backlog, greater computer literacy among managers, decreased software and hardware costs, increased hardware capacity, and higher hardware and software quality.

Some researchers have suggested that the more important reasons for management development of DSS are managerial and organisational. Fahy and Murphy (1996) found in a study that some of the technical reasons are valid but 
these do not give a full insight for management development of DSS. In summarising their study, they say: “...it is real management issues that are the key devices behind these systems [management developed systems] and that the development of these systems is an integral part of the activities of managers." (Fahy and Murphy, 1996, p. 140). Carlsson (1988) found, in a study of management development of DSS, that spreadsheet program usage by managers can be a means of changing a manager's experiential learning cycle' in two major ways. First, by using a spreadsheet program, some of the learning modes can be easier to accomplish and spreadsheet program usage can also lead to a higher quality in a learning mode. Second, the use of an spreadsheet program can speed up some of the learning modes and the whole learning process.

Although there are positive effects of management development of DSS, there are at the same time some "problems in paradise". One of the major problems is related to modelling errors (Panko, 1997a). For a good summary of the many studies on modelling errors see Panko, (1997b), a website on spreadsheet research with a focus on spreadsheet errors with implications for spreadsheet developers and development policies. In addressing such modelling problems, several recommendations, rules, and policies have been suggested by Panko (1988). Others have suggested validation procedures and frameworks (Finlay and Wilson, 1997). Although these rules, recommendations, etc., might lead to efficient development of error-free DSS there is no guarantee that they will lead to effective management development of DSS. They might just lead to efficient management development of DSS but the systems may be less effective or ineffective and, in some cases, meaningless. This suggests that we have to address the development process in context. Since management development of DSS, using an evolutionary DSS design approach, is common in many organizations, it is wise to examine the effects of such an approach to DSS design. In the following, some negative effects of management developed DSS will be pointed out, and some alternative approaches to DSS design will be discussed.

Another problem identified by researchers is the productivity problem, which can be exemplified by Edberg and Bowman's (1996) laboratory study of developer productivity. They found that surrogate IS professionals produced higher-quality applications and were much more productive than were end users. Studies like this

Kolb (1984) argues that an effective learning process can be “... described as a four stage cycle involving four adaptive learning modes - concrete experience, reflective observation, abstract conceptualization, and active experimentation" (ibid., p. 40). Concrete experience means that a learner is involved in new experiments - ideally a learner should involve himself fully, openly, and without bias in these experiments. Reflective observation takes place when a learner observes and reflects on his experiences. Abstract conceptualization means that a learner creates and changes concepts that integrate his observations into logically sound theories by, for example, developing and changing mental models. Active experimentation means that a learner uses these theories in the form of, for example, mental models to solve problems and make decisions. 
one suggest that managers might be relatively less efficient in developing DSS. However, the studies by Fahy and Murphy (1996), Carlsson (1988), and others, suggest that managers can develop effective DSS.

Management development of DSS is also directly related to the discussion of empowerment and decentralisation of decision making. Malone (1997) suggests that empowerment is not just a fad that will soon pass away. He argues that greater decentralisation is "... a response to fundamental changes in the economics of decision making enabled by new information technologies." (Malone, 1977, p. 34). He argues that dependent, decentralised decision makers will be increasingly important to organisations in the knowledge-based economy (see Wyner and Malone, 1996, for a mathematical proof that changes in IT will lead to more connected, decentralised decision-making structures in organisations. ${ }^{2}$ ) A likely consequence of Malone's ideas is that management development of DSS will increase in importance but, as we will argue, researchers and practitioners should focus much more on managerial and organisational issues.

The remainder of this chapter is organised into five sections. The first section discusses some negative effects of management development of DSS. The second section presents alternative approaches that can be used to overcome some of the negative effects. The third section presents a case study where an intervention was undertaken to address some of the noted problems. In the fourth section we discuss what is the value of management development of DSS. The discussion is based on the resource-based view of the firm. The section opens up new challenges for practitioners on how to manage and assess management development of DSS. The section also raises new research questions. The final section provides a conclusion and a discussion on future research.

This paper is based on a more or less systematic series of studies of management development of DSS carried out over the last ten years - for some of the results, see Carlsson (1988, 1989, 1991, 1994). We have also profited from other researchers' qualitative and quantitative studies on management development of DSS, for example Avdic (1994) and Fahy and Murphy (1996).

\section{MANAGEMENT DEVELOPMENT OF DSS: PROBLEMS IN PARADISE}

It is widely believed that management development of DSS, as well as DSS development in general, requires an approach which is distinct from the traditional Systems Development Life Cycle (SDLC). Several authors have pointed out that SDLC approaches are not suitable for DSS development (see, for example, Keen and Scott Morton, 1978; Ginzberg, 1978; Sprague and Carlson, 1982; and Sprague and Watson, 1996). In his analysis of different schools of IS development,

It should be noted that Wyner and Malone mainly consider two dimensions: 1) the value of the remote decision information used, and 2) the costs of communicating the remote decision information. 
Iivari (1991) suggests that the "...most significant contributions of DSS concern the IS development process. DSS directed the primary focus away from integrated MIS development governed by an overall MIS plan to a problem-oriented, small scale development of individual DSS applications. The very first DSS in the early 1970s also indicated the need for a flexible development process incorporating ideas of prototyping and in particular of evolutionary development" (ibid, p. 253).

Several alternative DSS approaches to SDLC have been launched, with names like iterative and evolutionary design (Lucas, 1978; Earl, 1978), adaptive design (Keen, 1980), middle-out design (Ness, 1975; Hurst et al., 1983), l'approche évolutive (Courbon, 1996), and expanding subsets (Moore and Chang, 1983).

Early research and experimentation in evolutionary design was done at the University of Grenoble by Courbon and associates (Courbon, 1996; Courbon et al., 1978). Courbon et al. suggest that an evolutionary design approach is characterised by the building of a version of the DSS, using it, evaluating it, refining it, and so on. There are several essentials to remember when developing an evolutionary design. First, it is critical to identify an important decision task. Secondly, the identified decision task has to be broken down into subtasks. This means identifying a part of the decision task that the potential user (manager) thinks is important and critical and for which it is possible to "quickly and easily" build a DSS. It is the potential user who is in the "driver's seat" while identifying the decision task and the subtasks. Thirdly, a "small" but useful DSS for the subtask(s) is developed. Fourthly, the DSS is used in "daily life", evaluated, and enhanced and modified.

From the experience of our own studies, as well as other researchers studies of management development of DSS where evolutionary DSS design have been used, it seems that this design approach can lead to several problems and negative effects. For example:

- A manager can get carried away by the technology at the expense of his primary tasks. We have seen highly-paid managers building and changing their DSS instead of having an assistant do the job to a lower cost and probably with a better result.

- A manager can get carried away by the "bells and whistles" of his DSS Generator - building what he thinks is a fancy DSS - instead of concentrating on the content of the DSS.

- Managers are in many cases "barefoot modelers."

- Managers have limited ability to identify complete and correct requirements for their DSS.

- A manager's lack of knowledge and acceptance of application assurance procedures for development and operation can lead to problems in the form of: 1) reluctance to test a system, 2) reluctance to document a system, 3) reluctance to include validation, especially validation of input data, 4) 
reluctance to include audit trails, including processing trails, and 5) reluctance to have operating controls, e.g. to check that all input data have been entered and results are compared to independent control figures (Davis, 1989).

Although the above problems are serious in themselves, we feel that a more serious problem, in the long run, is that evolutionary design and continuous development of decision tasks seem to lead to exploitation of current decision tasks. Henderson and Ingraham (1982) point out that evolutionary design seems more often to be a convergent process than a divergent process - see, also Davis (1989) and Cooprider and Henderson (1990/91) for the same point.

Evolutionary design and continuous development can be characterised as an anchoring and adjustment design approach. The concept of anchoring and adjustment is borrowed from Kahneman et al. (1982). They suggest that "anchor and adjust" can be a problem solving bias and hence in many DSS design situations a less good way to behave as a designer. Anchoring and adjustment in DSS design means that a developed DSS tends to be the result of minor adjustments of the current decision tasks (the anchor point). Stabell (1983) points out that, in prototyping and evolutionary design, there is no direction of the changes to be achieved. In using this design approach, it is easy to "...fall into a 'usability trap', the development of systems that are useable and used, but not very useful" (Stabell, 1983, p. 228). Carlsson (1984) and Marsden and Pingry (1986a, b, 1988) also criticise such approaches as non-directed change processes which do not make use of explicit purposes and goals to guide the design process.

In recent years, system restrictiveness has been discussed (Silver, 1991) mainly in terms of physical system restrictiveness. This "...signifies that system restrictiveness can be understood by examining the presence or the absence of certain system features, and that the system restrictiveness can be easily manipulated by including or excluding particular features." (Chu and Elam, 1990, p. 195). Chu and Elam propose another type of system restrictiveness: induced restrictiveness, which is a form of restrictiveness that "...manifests itself when the users of a DSS predominantly employ a particular decision process or a small set of decision processes, even though the system also physically permits a complementary process or an array of other decision processes which somehow tend to be ignored by the users. The presence of this effect would indicate that the system users are induced toward employing a particular process or processes." (Chu and Elam, 1990, p. 195).

In a laboratory study, Chu and Elam found that a spreadsheet program (Lotus 12-3) tended to induce an incremental decision process. Our own field studies suggest that in decision situations where there are no strong pressures for a synoptic decision process ${ }^{3}$, use of a DSS Generator to build a DSS is likely to induce an

A synoptic decision process is characterized by an unbiased search for a solution and makes no use of an existing solution. In many cases, an existing solution is seen as a hindrance to discovering innovative solutions. 
incremental decision process, i.e., anchor and adjust. On the other hand if, in a decision situation, there is strong pressure to do so, the DSS user can choose a synoptic decision process and employ a DSS Generator to build a DSS that can be used in that decision process.

Our studies suggest that, in general, a DSS Generator does not induce a synoptic decision process. Tentatively, it can be suggested that in a decision task in which there is some kind of anchor point - an existing solution or procedure - a DSS Generator will induce an incremental decision process unless a DSS designer deliberately chooses a synoptic decision process.

If the above is true, the question if this is good or bad for an organisation is an important one. Perusing the organisational learning literature, we suggest that, from an organisational point of view, DSS design as exploitation of current decision tasks might in the long run lead to some unwanted consequences. For example, March, in discussing organisational learning, points out that a "... central concern of studies of adaptive processes is the relation between the exploration of new possibilities and the exploitation of old certainties." (March, 1991, p. 71). Broadly, exploration "...includes things captured by terms such as search, variation, risk taking, experimentation, play, flexibility, discovery, innovation" and exploitation "....includes such things as refinement, choice, production, efficiency, selection, implementation, execution." (ibid., p. 71). An organisation must engage itself in both exploration and exploitation to survive in the long run. March says, "...maintaining an appropriate balance between exploration and exploitation is a primary factor in system survival and prosperity" (ibid., p. 71).

In discussing the pros and cons of exploration and exploitation, March points out that "....adaptive processes characteristically improve exploitation more rapidly than exploration. These advantages for exploitation cumulate. Each increase in competence at an activity increases the likelihood of rewards for engaging in that activity, thereby further increasing the competence and the likelihood." (ibid., p. 73). Still, for an organisation it is critical to sustain a reasonable level of exploration. According to organisational learning theories, the tendencies to increase exploitation and reduce exploration are likely to become effective in the short run but potentially self-destructive in the long run (ibid.). If we take March's words on the relationship between exploration and exploitation seriously, the tendency to use DSS for exploitation, ceteris paribus, can in the long run be a disadvantage to an organisation. In other words, management development of DSS (exploitation of decision tasks) can be a powaqqatsi. ${ }^{4}$ It consumes resources that should have been used for exploration. This means that too much continuous development (exploitation) of decision tasks can in the long run be hazardous to an organisation.

+ Powaqqatsi. From the Hopi language, powaq (sorcerer) + qatsi (life). n. an entity; a way of life, that consumes the life forces of other beings in order to further its own life. 


\section{ALTERNATIVES TO CONTINUOUS DEVELOPMENT OF DECISION TASKS}

In one of the organisations we have been working with, the problem of convergent continuous management development of DSS design had become a problem. The question for the organisation was: How can we handle the situation in a positive way. For the organisation it was not possible to invest in more information technology and it needed its DSS. Before presenting the case, we discuss alternatives to continuous development of decision tasks. We focus on alternatives to evolutionary DSS design. We will discuss two concepts: strategic opportunistic DSS design (Section 3.1) and radical redesign of decision processes (Section 3.2). The purpose of these alternatives are that they should increase the likelihood of the development of effective DSS in an efficient way and also lead managers to avoid developing less effective or meaningless DSS.

The design and building of DSS can be described and discussed from what we call a macro and a micro perspective. In the micro perspective the focus is on the design and building process of a specific DSS, i.e. once a person has decided to build a DSS, how does he go about designing and building it? At the micro level, we can identify several system analysis and design approaches. One way to classify these approaches is on a scale with two end points. One end point is pure top-down design and building, where one starts with high-level goals for the system to be designed and built and breaks them down into smaller and less complex problems. Each of these smaller problems is then in turn broken down until one reaches a level of achievable actions. The other end point of the scale is pure bottom-up design and building, where one starts with identifying the bottom-level objects and actions that are required and then figures out how to put them together.

In the macro perspective, the focus is on building and using a DSS in the context of other information sources. It focuses on questions such as: When and why does one build a DSS? A new or redesigned DSS can be viewed as a new or changed information source. White (1975) made a distinction between primary and secondary decisions. A secondary decision is defined as a decision that is related to the choice of information and methods to be used in addressing the primary decision problem. Our notion of macro level design falls under White's definition of a secondary decision. Stabell $(1975,1983)$ also discussed the relationship between secondary decisions and the design of DSS, stressing that a DSS designer should also consider what other information sources - beside the DSS - a decision maker uses or might use in his primary decisions.

\subsection{Strategic opportunistic DSS design}

The concept of strategic opportunistic DSS design has its roots in work by HayesRoth and Hayes-Roth (1979), Anderson (1983), and Isenberg (1988). Hayes-Roth and Hayes-Roth (1979) used the concept of opportunistic planning to describe multiple asynchronous processes that a person uses when planning whereby he or 
she can act opportunistically as the current situation suggests various opportunities for development. Anderson (1983) used the concept of opportunistic model in his discussion on human cognition and especially control of cognition, i.e. how human cognitive systems choose, consciously or unconsciously, what to process. In writing on managerial thinking, Isenberg $(1987,1988)$ used a related concept, strategic opportunism, to describe "... the ability to remain focused on long term objectives while staying flexible enough to solve day-to-day problems and recognise new opportunities." (Isenberg, 1987, p. 92). Isenberg's research suggests that effective managers strike this balance.

Here, we introduce strategic opportunistic DSS design as an approach for management development of DSS. In the macro perspective, the concept refers to a process characterised as follows:

- The manager has an overall long-term focus, i.e. a focus on overall organisational purposes and goals, and on the purposes and objectives of different tasks. This long-term focus is guided by the manager's mental models, for example, of information sources, etc. Such mental models might be intuitive and implicit, but can also be explicit and externalised.

- The manager is flexible: he can solve problems not foreseen and anticipated, which is of special interest here when this is done by building a DSS.

- The manager can recognise new opportunities and he must be reflective. This means, for example, that during task accomplishment the designer can recognise new opportunities a DSS can give in handling the task. In other words, the manager has a strategic perspective to guide him; at the same time he also acts opportunistically.

In the micro perspective, strategic opportunistic DSS design refers to a process characterised by the following:

- The designer/builder (manager) focuses on the overall objectives and purposes of a DSS, although these objectives are not stated in the same form as those discussed in top-down approaches, and it might not be possible to use them in a traditional top-down process.

- The designer has a mental model of the DSS to be built before he starts to build it; this model might in part be externalised, for example, sketched on a piece of paper. The designer is flexible in that he can solve problems not foreseen in the incomplete mental model and/or in the externalised model; the design and building process is flexible. The designer can also see new opportunities while designing and building the DSS.

The most important aspects of strategic opportunistic DSS design are as follows First, the process is guided by an overall understanding of the situation at hand: it 
is strategic. The designer is guided by mental models of the situation. These models can be intuitive and implicit, but they can also in part be externalised. Secondly, the design process is opportunistic in that it is a flexible process that can be adapted to new circumstances, problems, opportunities, etc. The adaptation process is guided by the overall understanding of the problem, i.e. by the designer's mental models. Adaptation should not be interpreted as more or less defensive adjustment; instead adaptation should be interpreted as adaptable development, improvement, and growth. These two features make strategic opportunistic design different from other DSS design approaches. In discussing DSS design, Ginzberg and Ariav present a classification scheme for DSS design methods; the methods can be classified along a continuum (Figure 1).

Traditional

Traditional

DSS Process*

SDLC**

$\begin{array}{ccl}\begin{array}{c}\text { Evolutionary } \\ \text { design }\end{array} & \begin{array}{c}\text { Strategic } \\ \text { opportunistic } \\ \text { design }\end{array} & \begin{array}{l}\text { Decison } \\ \text { research*** }\end{array}\end{array}$

* i.e., those often put forward as the most suitable DSS design methods.

** like traditional SDLC in that it emphasises analysis and is prescriptive and design-oriented.

*** see Stabell (1983).

Figure 1 DSS design methods: Evolutionary design, strategic opportunistic design, and decision research.

Ginzberg and Ariav say, "Moving from left to right on this continuum generally implies (1) more effort (e.g., time) spent 'up-front'; (2) decreasing 'respect' for the current decision making process; (3) an increasingly normative approach; (4) increasing attention to ultimate 'decisional impact,' i.e., change in actual performance; and, as a result, (5) potentially more radical impact on the decision situation and outcomes" (Ginzberg and Ariav, 1986, pp. 52-53). Moore and Chang (1983), in discussing DSS design, distinguish between "weak" and "strong" design: "The 'weak' versus 'strong' design dimension distinguishes those designs that follow the user's preferences and personal decision-making style from those that consciously attempt to manipulate or refine the user's approach to problem solving" (ibid., p. 188). Weak design methods will be on the left of the continuum and strong design methods on the right of the continuum. On the left hand side of the continuum we have prototyping and evolutionary design. As discussed above, these approaches have been put forward as suitable DSS approaches, more or less as panaceas. These approaches can be regarded as mainly 
opportunistic design approaches. Strategic opportunistic design is placed in the middle of the continuum and should be seen as mainly an approach to enhance evolutionary design. How one can get a manager DSS designer to become a strategic opportunistic designer will be discussed in Section 4. Meanwhile, the next section takes a closer look at macro level design.

\subsection{Radical redesign of decision processes}

In recent years, we have witnessed a growing interest in business process redesign. This growing interest can be found among researchers as well as among practitioners. Some researchers and practitioners have suggested that continuous, incremental product and process improvements, though still essential, are in many cases no longer sufficient if an organisation will stay or become competitive and effective - see, for example, the discussions in Davenport (1993), Hammer (1990), Davenport and Short (1990), Handy (1990), and Hammer and Champy (1993). The goals of business process redesign and process innovation are, for example, to achieve major reductions in process cost or time, or major improvements in flexibility, quality, or service levels. Davenport suggests a five steps approach to business process innovation: "identifying processes for innovation, identifying change enables, developing a business vision and process objectives, understanding and measuring existing processes, and designing and building a prototype of the new process and organisation." (Davenport, 1993, p. 25). It should be noted that when Davenport talks about processes he has in mind broad and inclusive processes. He proposes that most companies, even very large and complex ones, can be broken down into fewer than 20 major processes.

Using what we have presented and discussed above we propose a taxonomy for DSS design approaches. The taxonomy uses two dimensions: level of change (outcome) and frequency (Figure 2). In the figure we have classified various DSS design approaches. It is important to note that incremental improvements and radical innovations are not really.distinct types, but a whole continuum, with low incremental improvements at one end of that continuum and highly radical innovations at the other end. We can find changes of all shades of grey along the continuum. Continuous improvement can also be viewed as a continuum. From situations where it only takes a couple of hours or days to design, build, implement, and use a new or different version of a DSS to situations where one uses an approach that is close to traditional systems development.

The lines that separate the cells are, in reality, hard to draw. Traditional SDLC approaches (Cell A) have been used to successfully design and implement DSS (Hogue and Watson, 1984; Findley, 1983). DSS design approaches that are like traditional SDLC - different forms of life cycle and waterfall models - seem to lead to incremental improvements. These approaches often take, as a starting point, existing decision tasks. They often have a "narrow" functional scope, for example, 
they often take current tasks, functional units, and responsibilities as given. The approaches are "single shot" approaches: development of a DSS is carried out as a project with a relatively clear start and end.

However, even if a DSS is developed as a project it will, as most CBIS do, require maintenance: there will be a need for changes in the DSS. This may include "...reactive maintenance, or bug fixes; interactive maintenance, or maintenance that better supports present user interaction with the system; and proactive maintenance, or maintenance that will enable the DSS to keep abreast of needs and technology as each evolves over time." (Sage, 1991, p. 187). The latter type of maintenance is close to continuous improvement. One problem with Cell A approaches is that, since they do not make radical changes in old decision processes and tasks, it is easy to end up speeding up messy tasks and processes.

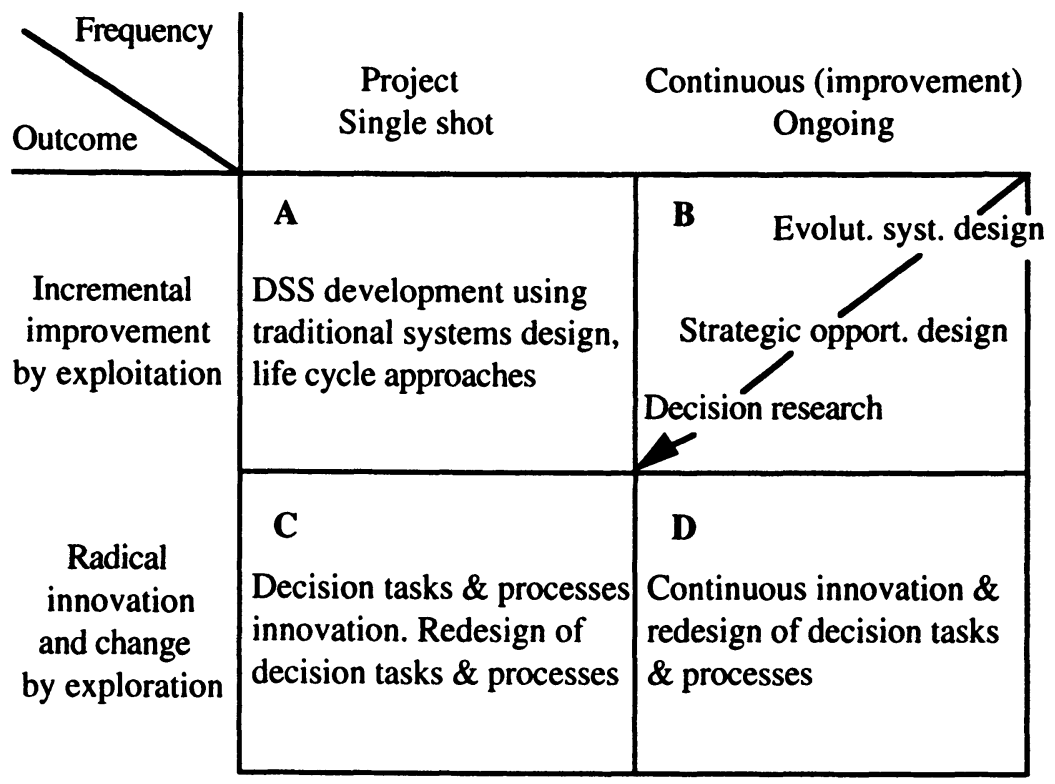

Figure 2 DSS design approaches to decision improvement.

The ideas underlying this the taxonomy can be found in Davenport (1993), who focused on business improvement, but we have adapted his ideas here to decision processes and decision improvement. The various DSS design approaches we classified above, according to the scheme suggested by Ariav and Ginzberg (1986), can be considered as approaches likely to lead to incremental improvements. Hence these approaches are placed in the cell incremental improvement and continuous improvement, that is, Cell B. Moving from the right upper corner to the left lower corner in this cell generally implies that more effort is spent up-front; a decreasing respect for the current decision making process; an 
increasingly normative approach; an increasing attention to ultimate decision impact (change in actual performance); and, as a result, a potentially more radical impact on the decision tasks and outcomes.

Approaches in Cell $\mathrm{C}$ are intended to achieve radical decision improvement. At the heart of innovation in, and redesigning of, decision processes lies the notion of discontinuous thinking (Handy, 1990), that is, identifying, questioning, and abandoning those outdated rules and fundamental assumptions that underlie current decision processes. The approaches in Cell $\mathrm{C}$ would focus on an organisation's decision processes infrastructure, working on it. to change the organisation's ability to make decisions and take action. As far as we know, there are no such DSS design approaches in existence at present. There are, however, CBIS approaches that can be considered total or global, in that they focus on a whole organisation or a major part of the organisation. These approaches can be considered as enterprise modelling approaches. Examples are IBM's Business Systems Planning (IBM, 1984) and information engineering (Finkelstein, 1992).

Enterprise modelling and information engineering approaches have in common that they view data and information as corporate resources. These resources must be managed from an overall organisational view. In Business Systems Planning (BSP), the goal is to discover a stable information architecture that supports all of the business processes. One of the first steps in BSP is to define business processes where business processes are defined "...as groups of logically related decisions and activities required to manage the resources of the business" (IBM, 1984 , p. 29). As long as the business processes remain basically the same, then the information architecture will be stable. An assumption is that as long as an organisation stays in the same business, the business processes will remain relatively constant. The approaches use the information architecture as a basis for future information systems planning, that is, to identify the CBIS that should be developed in the next years. As -we see it, approaches like BSP take a workflow view of an organisation. Important in a workflow view is to create structures and administrative processes that fit an organisation's production processes and operations.

Cell $\mathrm{C}$ approaches are to a large extent based on the assumptions of stability and continuity. Some writers on management and organisation design suggest that these assumptions are unrealistic. Tapscott (1996), writing about innovation, says that in the "new digital economy", continuous improvement or single shot radical redesign will not be enough. He suggests that many organisations have to continuously innovate new products and services, and hence redesign many of their business processes continuously. Nohria and Ghoshal (1997) say that an increasing number of firms must continuously innovate to maintain and enhance their performance. Boynton (1993) suggests that managers in organisations that face frequent, rapid, unpredictable changes in their competitive environments must create organisations that are dynamically stable. These are organisations that are 
capable of serving the widest range of customers and changing products and service requirements (dynamic) and at the same time build on long-term process capabilities and the collective organisational knowledge (stable). Boynton says that one of the most critical steps in building these organisations is strategic management of information. An implication of the above for management development of DSS is that infrastructural issues will become even more critical.

In Cell D, the challenge is to develop approaches that can be used to create DSS supported decision processes, that can rapidly be radically redesigned, and that build on previous process capabilities and the collective knowledge of the organisation. This means that IS and DSS managers will have to focus much more on organisational and managerial issues.

On the other hand it, should be noted that several business process redesign writers believe that radical levels of processes innovations are difficult to maintain and co-ordinate on a continuous basis (Davenport, 1993; Hammer and Champy, 1993). They say that employees and organisations need periods of rest and stability between radical innovation initiatives. These in turn may be no more than management fads (Jackson, 1995).

Having presented the framework and the alternative approaches we now turn to our case study to illustrate two of the concepts, strategic opportunistic DSS design and radical redesign of decision processes.

\section{A CASE STUDY ON STRATEGIC OPPORTUNISTIC DSS DESIGN AND RADICAL REDESIGN OF DECISION PROCESSES}

The organisation (Alfa) in our case study is a public sector organisation. Its main field of action is to provide child care. In the mid 1980s, there was major frustration in the organisation due to the development backlog for its CBIS/DSS The few DSS that had been implemented - mainly for budget simulations - had been developed using a traditional SDLC approach (State I in Figure 3). At that time, it was decided that personal computers should be installed - this was a major investment for the organisation. Approximately a quarter of the 150 personal computers that were installed replaced dumb terminals and stand-alone word processing machines. The personal computers were equipped with suitable software. The basic software for DSS applications were a spreadsheet program, a database package, and a statistical program. A computer education programme for all personnel working with administrative tasks was launched. The goal of the programme was that all personnel working with administrative tasks should become computer literate. This goal was fulfilled.

By the beginning of the 1990s, personal computers were being used fairly well in the organisation. Many management developed DSS were in use. Most of the managers (users) were satisfied with the situation. They had been able to build DSS that they felt were useful. The approach used to build and rebuild the individual DSS was evolutionary design (State II in Figure 3). At the same time, it had 
become apparent to Alfa's executive team and various managers that, from an organisational perspective, the situation was less than satisfactory. The individual DSS were built from the task perspectives of the individual builders (managers) rather than from a common organisational perspective. For example, those DSSs which should reflect Alfa's goals and policies did so in quite different ways, and some DSS reflected personal views that were contradictory to the organisation's goals and policies. Thus, decisions that should be consistent across the organisation were not at all consistent. This meant that the situation, from an organisational perspective, was a little bit too anarchistic and chaotic.

At the same time, there was external pressure on the organisation. During the late 1980s and early 1990s, there were major changes in the city's administration and in the public sector in general. Discussions, decisions, and implementation of privatisation and outsourcing were taking place. Privatisation and outsourcing meant changes in goals and boundaries of different public sector organisations, as well as of other organisations. Although this was a slow process, these changes progressively led to changes in decision authorities, responsibilities, etc., that is, changes in decision processes.

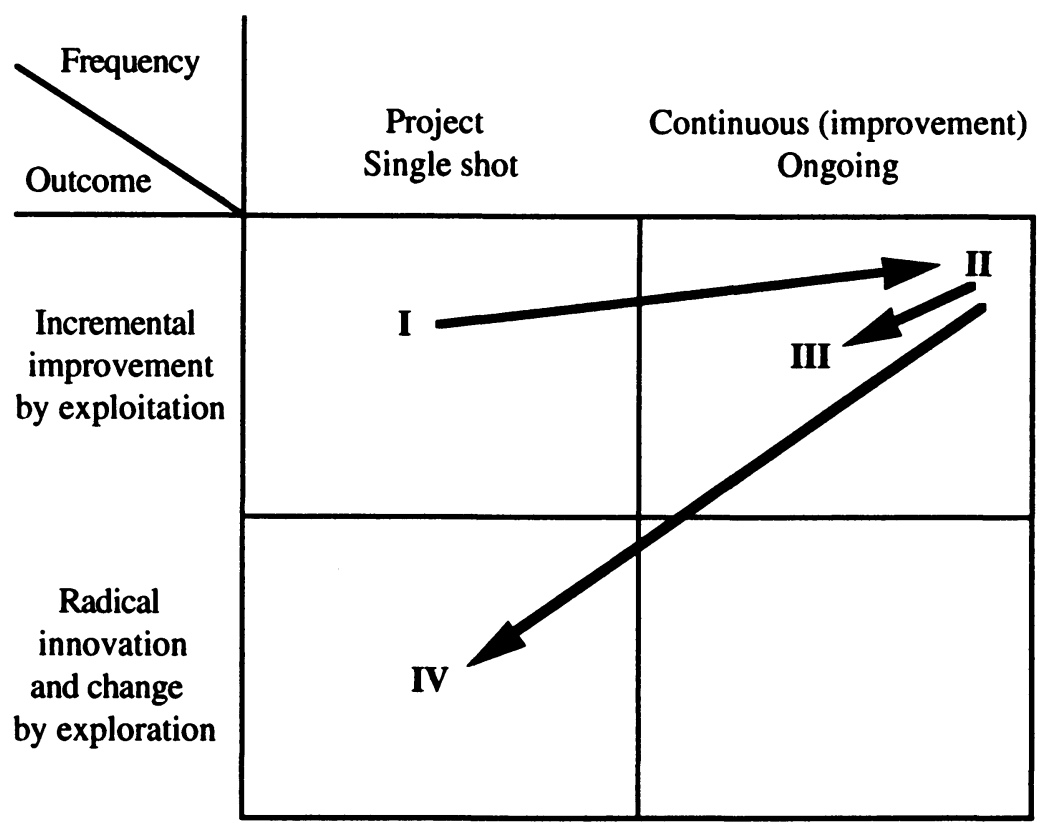

Figure 3 DSS design approach used in the organisation prior to user DSS design (I). User DSS design approach used in the organisation (II) and intended changes (III and IV). 
It should be noted that Alfa had and has scarce resources which meant that there were, and are, few resources to support the "transformation process". Since Alfa is a public sector organisation, it is not allowed to do what ever changes it would like to do: laws, agreements, political decisions, stakeholders, etc., are restricting the decisions and actions Alfa can take. After discussions in Alfa - during the summer of 1993 - it was decided by the executive team that the two approaches discussed above should be tried in order to address Alfa's problems with management development of DSS. This means that two different approaches would be used. The first approach would be employed to try to get the manager DSS designers to become strategic opportunistic designers, that is, a move to State III in Figure 3. The second approach would be employed to prepare the organisation for radical redesign of decision processes (a move to State IV in Figure 3). A small project team ( 5 persons) was established with the responsibility to start the change programme.

\subsection{Learning to become a strategic opportunistic DSS designer}

The purpose of this intervention was to get the managers to become more strategically minded in their DSS design, in other words, to move to state III.

With regard to micro level design, it was decided by the project team that different means should be used. In Alfa, there were no formal controls on DSS design, building, or use. As seems to be typical, the planning and control mechanisms that existed focused on hardware and software issues. The control mechanisms addressed problems like: what hardware and software should be used in the organisation, how hardware should be maintained, and how a new version of a software should be distributed. This means that there was no support to help managers act as good DSS designers. Panko (1988) and Ronen et al. (1989) have proposed rules, guidelines, and principles of good practice with respect to designing and building small DSS using a spreadsheet program. These rules, etc., cover such subjects as proper design, screen design, and construction of equations. Ronen et al.'s suggestions resemble suggestions for using structured techniques in "traditional" systems development using, for example, hierarchical or modular design. So far, these kinds of techniques have not been on the agenda in Alfa's spreadsheet program courses. The team expected that Ronen et al.'s approach has to be properly packaged - taught in courses, for example, and supported by handbooks and software - in order to have any impact.

The project team assessed that the DSS manager- designers had a passive knowledge of the actual DSS Generators. They decided that, instead of taking a traditional approach in the course, three specific means should be used. First, a DSS design handbook for users was developed. Second, good DSS examples, developed in the spreadsheet program, were distributed to the DSS managerdesigners. The DSS examples were all related to administrative tasks in Alfa and were distributed on local area networks and disks. Third, a "train the trainee" 
approach was used to increase the likelihood that the handbook and the examples would have an impact on the designers.

With regard to macro level design, it was decided that a "train the trainee" approach should be used. The same persons were educated as were for micro level design. In all, 20 persons were taught strategic opportunistic DSS design in a two day course. The DSS handbook contained a short discussion on what a secondary decision means and two short cases. The cases were written to show the differences between strategic opportunistic DSS design and opportunistic DSS design, and showed what methods and techniques that could be used in strategic opportunistic DSS design.

These ways of educating and influencing the DSS manager-designers to become strategic opportunistic designers were implemented during the last months of 1993. No formal follow up study was done, but semi-structured interviews conducted with some persons suggest that there were changes in the behaviour of the DSS manager-designers and that these changes were in the desired direction.

\subsection{Preparing for redesign of decision processes}

A second task for the team was to start a process that in the end should lead to the redesign of Alfa's decision processes and the design of new decision processes (state IV).

It was decided that a high-impact approach should be used, which meant deciding which business processes were most in need of redesign. ${ }^{5}$ The first step was to identify or establish the existing decision processes, which would then provide the basis for identifying which decision processes to change. As pointed out in the redesign literature, a process, to be improved, must first be understood and regularised. We found that what Davenport says about management processes was quite true in the case of Alfa: "...of all the processes in an organisation, management processes are the most poorly defined, and least likely to be viewed in process terms" (Davenport, 1993, p. 275).

From our initial discussions and interviews with the personnel we found that the fundamental issue was: what are the purposes of Alfa's different decisions and decision processes? We used Brunsson's $(1985,1989)$ alternative interpretation of decision making as our base for this issue. The "standard" view of decision making is that the purpose of decision making is to choose. Brunsson proposes three alternative purposes of organisational decision-making: 1) decision making as a

Davenport (1993) says that the main generic business processes potentially in need of process innovation include product and service development and delivery (including research, design, engineering, logistics, and manufacturing); customer-facing activities (including order management and marketing); and management activities (including strategy formulation, performance measurement and reporting, planning and budgeting, human resource management, resource allocation, and infrastructure building). 
mobiliser, 2) decision-making as responsibility allocation, and 3) decisions as legitimisation. A problem in Alfa, as in many organisations, is how to achieve coordinated and collective actions. Decision-making and decisions can sometimes be used for this purpose. The key is to secure commitment from actors, and hence link actors to action in advance.

Several decisions which had, as their main purpose, to establish and maintain commitments were identified in Alfa. In many decision situations goals, alternatives, etc., can be uncertain, but uncertainty can also concern decisionmakers (decision-making as responsibility allocation). Decision-making is sometimes used for clearly pointing out who are the decision-makers. In Alfa we found decisions that were employed for allocating responsibility by making the decision-makers visible. Alfa can, in part, be considered a decision-oriented organisation. This means that decision making constitutes important activities and decisions are important outputs. Normally it is assumed that there is a connection between decisions and actions, büt sometimes decision-oriented organisations, like governments and public organisations, are eager to publicly declare some of their decisions, although they might not be connected to actions (decisions as legitimisation).

The result was that several decision processes were identified and described, and the purposes of these decision processes were pointed out. Although the descriptions of the decision processes were fairly crude, they led to intensive discussions. This work also led to changes in the personnel's mental models of tasks and decisions processes. The project was halted in the spring due to an upcoming election. The project was not restarted after the election. The main reason was that other issues and problems had to be addressed and solved.

Having presented the framework, the alternative approaches, and the case study, we will address, in the next section, the question: what is the organisational value of management development of DSS, and what is its relationship to firm performance?

\section{ASSESSING MANAGEMENT DEVELOPED DSS: A RESOURCE-BASED VIEW}

In trying to address the question of value, we looked for theories and frameworks that could suggest when management development of DSS matters, and in what way it matters. Most of the writing on the relationship of IT to performance of the firm has been based on an external view, focusing on the ways IT affects or might affect a firm's competitive environment. It has been suggested that this is not enough. The focus must also be on strengths and weaknesses of a firm. The resource-based view of the firm, developed by Wernerfelt (1984), Barony (1991, 1995), and others, has this focus. This view makes two assertions about firms. The 
first is resource heterogeneity, which means that resources and capabilities ${ }^{6}$ may be heterogeneously distributed across competing firms. The second is resource immobility, which means that these differences in resources and capabilities may be stable over time. A firm's resources and capabilities include all financial, human, physical, and organisational assets utilised by a firm to develop, manufacture, and deliver services and products to its customers. According to Barney $(1994,1997)$, the following four questions may be asked about any resource or capability to assess whether or not it can be a source of competitive advantage:

- "The Question of Value. Do a firm's resources and capabilities enable the firm to respond to environmental threats or opportunities?" (Barney, 1997, p. 145)

- "The Question of Rareness. How many competing firms already possess particular valuable resources and capabilities?" (ibid., p. 148).

- "The Question of Imitability. Do firms without a resource or capability face a cost disadvantage in obtaining it compared to firms that already possess it?" (ibid., p. 150).

- "The Question of Organisation. Is a firm organised to exploit the full competitive potential of its resources and capabilities." (ibid., p. 160).

Barney used these four questions to form a Value, Rareness Imitability and Organization (VRIO) framework to understand the potential competitive implications of exploiting any of a firm's resources and capabilities (Table 1).

The VRIO framework can be used to evaluate the competitive implications of management development of DSS. For any specific DSS, decision task, or decision process, it is possible to assess these implications. A specific DSS may be vied as consists of three components 1) the data component, 2) the model component and 3 ) the dialogue component (Sprague and Watson, 1996). For each of the three components, and for the total DSS, it is possible to evaluate: if they are valuable, if they are valuable, if they are costly to imitate, and if they are exploited by the firm.

We have seen DSSs where the data component and the model component ,when exploited by the firm. have given that firm a competitive advantage. In one firm, the management developed a DSS whose data base contained sales data that helped the firm make better marketing decisions. Since this data was not costly to collect, it gave the firm a temporary competitive advantage. It took the firm's competitors about one year to establish their own data bases in response.

In another firm the management developed a DSS which, when exploited by the firm, gave it a sustained competitive advantage. The firm spent several years developing various market indices which were incorporated as models in the DSS.

6 Writers on the resource based view define these and related concepts differently but for our purposes they can, and will, be used interchangeable. 
These indices were better predictors of market changes than were the official indices, available to all the firms in the industry. The DSS was used in several contexts: from tactical decision processes, like production planning, to strategic decision processes, like production capacity investment decisions. The DSS, and its use in the various decision processes, was valuable to the firm. The competitors did not have this resource and they could not imitate it in an inexpensive way, or substitute it. The resource was exploited well by the firm.

Table 1 The VRIO framework for evaluating the competitive implications of a firm's resources and capabilities (Barney, 1997, p. 163).

Is a resource or capability ...

\begin{tabular}{|c|c|c|c|c|c|}
\hline Valuable? & Rare? & $\begin{array}{l}\text { Costly } \\
\text { to } \\
\text { imitate? }\end{array}$ & $\begin{array}{l}\text { Exploited by } \\
\text { the } \\
\text { organization }\end{array}$ & $\begin{array}{l}\text { Competitive } \\
\text { implications }\end{array}$ & $\begin{array}{l}\text { Economic } \\
\text { performance }\end{array}$ \\
\hline no & - & - & $\Lambda^{\text {no }}$ & $\begin{array}{l}\text { competitive } \\
\text { disadvantage }\end{array}$ & $\begin{array}{l}\text { Below } \\
\text { normal }\end{array}$ \\
\hline yes & no & - & & $\begin{array}{l}\text { competitive } \\
\text { parity }\end{array}$ & Normal \\
\hline yes & yes & no & & $\begin{array}{l}\text { temporary } \\
\text { competitive } \\
\text { advantage }\end{array}$ & $\begin{array}{l}\text { Above } \\
\text { normal }\end{array}$ \\
\hline yes & yes & yes & yes & $\begin{array}{l}\text { sustained } \\
\text { competitive } \\
\text { advantage }\end{array}$ & $\begin{array}{l}\text { Above } \\
\text { normal }\end{array}$ \\
\hline
\end{tabular}

Although the resource-based view of the firm, and the VRIO framework, are powerful, they have limitations (Barney, 1997). First, rapid and unpredictable changes in a firm's environment can change the value of a firm's resources. In the case that a firm has gained a sustained competitive advantage, because of its 
decision process and DSS, this advantage will not last forever. It can be displaced through revolutionary change in the firm's environment.

One way for a firm to prepare itself for such a change would be to design and develop decision processes and DSS that can support the firm in becoming dynamically stable (c.f. the discussion in Section 3.2). Second, the VRIO might suggest that firms and managers have a limited ability to create sustained competitive advantages. Obviously, this is not true. Third, data necessary for a VRIO analysis can be hard to collect and several things are hard to measure.

\section{DISCUSSIONS, CONCLUSIONS, AND FURTHER RESEARCH}

In this chapter we have focused on management development of DSS - a major factor in business computing - and how this is in different ways are related to organisational change and transformation. Many management -developed DSS are developed using an evolutionary design approach. Even if evolutionary user DSS design has many positive effects, it seems that it can lead to too much exploitation of current decision tasks and, in the long run, be harmful to an organisation. We presented two approaches that could be used to overcome some of the problems with evolutionary design. The strategic opportunistic design approach can be seen as an enhancement of traditional evolutionary design. The aim is that managers should become more strategically oriented in their secondary decisions as well as in their DSS building activities. If we assume that strategic opportunistic DSS design can be effective for management development of DSS, there, of course, remain several unanswered questions and research topics such as: How do we best teach managers to become strategic opportunistic DSS designers? Can such a design approach be "formalised" and supported? Is it possible to design DSS generators that can support a user to act more strategically when designing?

A second approach discussed was redesign of decision processes. Unless a very expert-oriented approach is used, the first step would be to have the members of an organisation change their perceptions of decision tasks and processes. This is in line with the Scandinavian tradition of organisational change and CBIS development. Our case study suggests that the two approaches can be useful in overcoming some of the negative effects of management development of DSS. The goals of the two approaches are quite different. The goal of the first approach is to change the behaviour of the DSS user-designers without radically changing an organisation's decision processes. The goal of the second approach is to challenge and strive for radical changes in an organisation's current decision processes.

Looking at the history of DSS, one sees that the focus has changed over the years: from group and organisation to the individual and back to the group and organisation. Early DSS studies, like Scott Morton's (1971) study, focused on non-individual DSS. This was partly due to the high cost of hardware, software, 
and cost per line of code generated for the DSS - it was not economically justifiable to build individual DSS. The advent of personal computers made it possible to build small individually oriented DSS without too much effort and high costs. Hackathorn and Keen (1981) were among the first to distinguish among individual, group, and organisational DSS. In recent years, we have witnessed a growing interest in group and organisational DSS (see, for example, Lee et al., 1988, and Nunamaker et. al., 1992). So far, most of the writings on organisational DSS have been on how to conceptualise and define ODSS and on the IT to be used in building ODSS. Very little has been done on the development of specific approaches for designing ODSS.

We feel that there is a need to develop DSS design approaches that are single shot approaches, but where the purpose is to achieve radical improvements through redesigning and reengineering decision processes. If we want such approaches to be based on decision making theories, one starting point could be the work of Huber and McDaniel (1986). They propose a decision-making paradigm of organisation design and provide sensitising concepts. They give guidelines, for example, on designing decision management systems. However, Huber and McDaniel do not provide any methods and techniques that can be used in design.

An interesting DSS development approach, more or less in line with Huber and MacDaniel's ideas, has been suggested by Adam $(1996,1997)$. This approach is based on social network analysis and stresses the multi-manager nature of most important organisational decision processes. It could be interesting to also look at workflow management approaches (Sherr, 1993) and approaches based on an organisation change view (Ferioli and Migliarese, 1996, Migliarese and Ferioli, 1997). These approaches could be complemented with more cognitively oriented approaches. At the same time, it should be noted that the research community do not seem to know exactly what constitutes management processes. A management process is often semi- or unstructured, more or less discontinuous, often ad hoc, in many cases based on intuition, and cognitive. This means that, in general, management processes are not a target for the same kind of process innovation that can be found for standard order management or manufacturing. There is a need to develop ways to combine decision process reengineering, as a discrete (project based) initiative with incremental initiatives for development of ongoing decision processes: i.e., taking an approaches that marries radical innovation and strategic opportunistic design.

In the case study above, we focused exclusively on Alfa's internal decision processes, but it is also possible to take a broader view on decision processes. concerning business process redesign, Short and Venkatraman (1992) suggest that it might be of greater strategic importance to an organisation to redesign business networks, that is, to reconceptualize the roles of the organisation and its key business processes within the larger business network. Short and Venkatraman's ideas can be transferred to decision process redesign. Instead of focusing on an organisation's decision processes infrastructure, one can focus on how to reconceptualize and redesign an organisation's decision processes within the larger 
decision network. It seems that Adam's $(1996,1997)$ approach could be useful to develop DSS within a larger decision network.

A relevant research issue to address in future is, of course, how the relationship between exploitation and exploration can be changed by providing different forms of easy-to-use computer-based tools. It should also be interesting to see if certain computer-based tools induce exploration or exploitation. Using a DSS for exploration of new alternatives may reduce the likelihood of learning and improvement of existing products/services and processes. Designing and implementing DSS for improvements of existing decision processes may make exploration less likely and attractive. A trend that is very clear is that IT and software for DSS generation is becoming cheaper, more powerful, and easier to use. Thus it is likely that DSS-supported exploitation will become easier and cheaper in the future. DSS-supported exploitation will probably be more rewarding than it used to be, at least in the short run. As far as we know, these issues have not been addressed in the literature, and there are no reported studies that have investigated them empirically. Another problem with the DSS design approaches in cells $A$ and $B$, in figure 2 , is that too much focus and efforts on developing stand-alone applications might lead to a neglect of the design and creation of a technology platform in an organisation which should be capable of supporting a variety applications, most of which have not yet been designed, or even foreseen.

In the previous section, we focused on the question of the value of management developed DSS. We suggested that one way to address this question could be through the resource based view, using the VRIO framework. while other researchers have suggested the use of the framework in IS research and practice (Andreu and Ciborra, 1996a, b; Mata et al. 1995), empirical research on its usefulness is needed. An implication of the resource base view of the firm is that managers and DSS personnel have to become more managerial and organisational oriented. Meanwhile, the standard view of DSS in the literature has been too technically oriented - the same point has been made by Murphy (1994).

\section{REFERENCES}

Adam, F. (1996) Experimentation with Organisation Analyser, a tool for the study of decision making networks in organisations, in Implementing systems for supporting management decisions (eds. P. Humphreys, L. Bannon, A. McCosh, P. Migliarese and J.-C. Pomerol), Chapman \& Hall, London. 1-20.

Adam, F. (1997) Can social network analysis provide a new analytical approach for DSS development and DSS research. Proceedings of the 5th European Conference on Information Systems, 413-426.

Anderson, J. R. (1983) The architecture of cognition. Harvard University Press, Cambridge, MA. 
Andreu, R. and Ciborra, C. (1996a) Core capabilities and information technology: an organizational learning approach, in Organizational learning and competitive advantage (eds. B. Moingeon and A. Edmondson), Sage, London, 121-138.

Andreu, R. and Ciborra, C. (1996b) Organizational learning and core capabilities development: the role of IT. Joumal of Strategic Information Systems, 5, 111-127.

Avdic, A. (1995) Work-integrated systems development with spreadsheet programs. Unpublished Licentiate dissertation, Linköping University, Linköping, Sweden (in Swedish).

Barney, J. B. (1991) Firm resources and sustained competitive advantage. Journal of Management, 17, 99-120.

Barney, J. B. (1994) Bringing managers back in: a resource-based analysis of the role of managers in creating and sustaining competitive advantages for firms, in Does management matter? - on competencies and competitive advantage (ed. A. T. Malm), Lund University Press, Lund, Sweden, 1-36.

Barney, J. B. (1995) Looking inside for competitive advantage. Academy of Management Executive, 9, 49-61.

Barney, J. B. (1997) Gaining and sustaining competitive advantage. AddisonWesley, Reading, MA.

Boynton, A. C. (1993) Achieving dynamic stability through information technology. California Management Review, 35, 58-77.

Brancheau, J. C. and Brown, C.V. (1993) The management of end-user computing: status and directions. ACM Computing Surveys, 25, 437-482.

Brunsson, N. (1985) The irrational organization: irrationality as a basis for organizational action and change. John Wiley \& Sons, Chichester.

Brunsson, N. (1989) The organization of hypocrisy: talk, decisions and actions in organizations. John Wiley \& Sons, New York.

Carlsson, S. A. (1984) Decision support systems: a critical assessment of two approaches for developing decision support systems, in Systems development by whom, for whom, and how? (ed. H.-E. Nissen), Swedish Work Environment Fund, Stockholm, 99-113 (in Swedish).

Carlsson, S. A. (1988) A longitudinal study of spreadsheet program use. Journal of Management Information Systems, 5, 82-100.

Carlsson, S. A. (1989) Why Johnny can't or won't spreadsheet. Scandinavian Journal of Information Systems, 1, 118-142.

Carlsson, S. A. (1991) DSS and unlearning: taking organizational environments into account, in Environments for supporting decision processes (eds. H. G. Sol and J. Vecsenyi), North-Holland, Amsterdam, 371-385.

Carlsson, S. A. (1994) Continuous development of decision tasks versus redesign of decision processes, in Proceeding of the IFIP WG8.3 conference on Decision support in organizational transformation (eds. B. Mayon-White, S. Ayestarán and P. Humphreys), San Sebastian, Spain, 137-154. 
Chu, P.C. and Elam, J. J. (1990) Induced system restrictiveness: an experimental demonstration. IEEE Transactions on Systems, Man, and Cybernetics, 20, 195-201.

Ciborra, C. (1994) The grassroots of IT and strategy, in Strategic information systems: a European perspective (eds. C. Ciborra and T. Jelassi), John Wiley \& Sons, Chichester, England, 3-24.

Cooprider, J. G. and Henderson, J. C. (1990/91) Technology-process fit: perspectives on achieving prototyping effectiveness. Journal of Management Information Systems, 7, 67-87.

Courbon, J. C. (1996) User-centred DSS design and implementation, in Implementing systems for supporting management decisions (eds. $\mathrm{P}$. Humphreys, L. Bannon, A. McCosh, P. Migliarese and J.-C. Pomerol), Chapman \& Hall, London, 108-123.

Courbon, J. C., Grajew, J. and Tolovi, J. (1978) Design and implementation of decision support systems by an evolutive approach. Working Paper, Institut d'Administration des Enterprises, Université des Sciences Sociales, Grenoble, France.

Davenport, T. H. (1993) Process innovation: reengineering work through information technology. Harvard Business School Press, Boston, MA.

Davenport, T. H. and Short, J. E. (1990) The new industrial engineering: information technology and business process redesign. Sloan Management Review, 31, 11-27.

Davis, G. B. (1989) CAUTION: User-developed systems can be dangerous to your organization, in End-user computing: concepts, issues and applications (ed. R. R. Nelson), John Wiley \& Sons, New York, 209-228.

Earl, M. J. (1978) Prototype systems for accounting, information and control. Accounting, Organizations and Society, 3, 161-170.

Edberg, D. T. and Bowman B. J. (1996) User-developed applications: an empirical study of application quality and developer productivity. Journal of Management Information Systems, 13, 167-185.

Fahy, M. and Murphy, C. (1996) From end user computing to management developed systems. Proceedings of the 4th European Conference on Information Systems, 127-142.

Ferioli, C. and Migliarese, P. (1996) A DSS design method based on organizational change, in Implementing systems for supporting management decisions (eds. P. Humphreys, L. Bannon, A. McCosh, P. Migliarese and J.C. Pomerol), Chapman \& Hall, London, 160-181.

Findley, J. J. (1983) Critical success factors for DSS implementation. Presentation at the Third International Conference on Decision Support Systems, DSS-83, June 27-29, Boston, MA.

Finkelstein, C. (1992) Information Engineering. Addison-Wesley, Reading, MA. 
Finlay, P.N. and Wilson J. M. (1997) Validity of decision support systems: towards a validation methodology. Systems Research and Behavioral Science, 14, 169-182.

Ginzberg, M J. (1978) Redesign of managerial tasks: a requisite for successful decision support systems. MIS Quarterly, 2(1), 39-52.

Ginzberg, M. J. and Ariav, G. (1986) Methodologies for DSS analysis and design: a contingency approach to their application. Proceedings Seventh International Conference on Information Systems, 15-17 December, San Diego, CA, 46-56.

Hackathorn, R. D. and Keen, P. G. W. (1981) Organizational strategies for personal computing in decision support systems. MIS Quarterly, 5, 21-27.

Hammer, M. (1990) Reengineering work: don't automate, obliterate. Hanvard Business Review, 68, 104-112.

Hammer, M. and Champy, J. (1993) Reengineering the corporation: a manifesto for business revolution. Harper Business, New York.

Handy, C. (1990) The age of unreason. Harvard Business School Press, Boston

Hayes-Roth, B. and Hayes-Roth, F. (1979) A cognitive model of planning. Cognitive Science, 3, 275-310.

Henderson, J. C. and Ingraham, R. S. (1982) Prototyping for DSS: a critical appraisal, in Decision support systems (eds. M. J. Ginzberg, W. Reitman and E. A. Stour), North-Holland, Amsterdam, 79-96.

Hogue, J. T. and Watson, H. J. (1984) Current practices in the development of decision support systems. Proceedings Fifth International Conference on Information Systems, November 28-30, Tucson, AZ, 117-127.

Huber, G. P. and McDaniel, R. R. (1986) The decision-making paradigm of organizational design. Management Science, 32, 572-589.

Hurst, G. E., Jr., Ness, D. N., Gambino, T. J. and Johnson, T. H. (1983) Growing DSS: a flexible, evolutionary approach, in Building decision support systems (ed. J. L. Bennett), Addison-Wesley, Reading, MA, 111-132.

IBM (1984) Business systems planning: information systems planning guide. International Business Machines Corporation, GE20-0527-4, White Plains,

Iivari, J. (1991) A paradigmatic analysis of contemporary schools of IS development. European Journal of Information Systems, 1(4), 249-272.

Isenberg, D. J. (1987) The tactics of strategic opportunism. Hanvard Business Review, 65, 92-97.

Isenberg, D. J (1988) Managerial thinking: an inquiring into how senior managers think. Book manuscript.

Kahneman, D., Slovic, P. and Tversky, A. (eds.)(1982) Judgement under uncertainty: heuristics and biases. Cambridge University Press, New York.

Jackson, M. C. (1995) Beyond the fads: systems thinking for managers Systems Research, 12, 25

Keen, P. G. W. (1980) Adaptive design for decision support systems. Data Base, 12, 15-25.

Keen, P. G. W. and Scott Morton, M. S. (1978) Decision support systems: an organizational perspective. Addison-Wesley, Reading, MA. 
Kolb, D. A. (1984) Experiential learning: experience as the source of learning and development. Prentice-Hall, Englewood Cliffs, NJ.

Lee, R. M., McCosh, A.M. and Migliarese, P. (eds.)(1988) Organizational decision support systems. North-Holland, Amsterdam.

Lucas, H., Jr. (1978) The evolution of an information system: from key-man to every person. Sloan Management Review, 19, 39-52.

Malone, T. W. (1997) Is empowerment just a fad? Control, decision making, and IT. Sloan Management Review, 38, 23-35.

March, J. G. (1991) Exploration and exploitation in organizational learning. Organization Science, 2, 71-87.

Marsden, J. R. and Pingry, D. E. (1986a) Problem structure and DSS design. Proceedings of the Nineteenth Annual Hawaii International Conference on Systems Sciences, 603-608.

Marsden, J. R. and Pingry, D. E. (1986b) Generating an optimal information system: PMAX-SLDC and the redirection of MIS research (or how to help Joe eat salmon). Journal of Management Information Systems, 3, 32-51.

Marsden, J. R. and Pingry, D. E. (1988) End user-IS design professional interaction - information exchange for firm profit or end user satisfaction?. Information \& Management, 14, 75-80.

Mata, F. J., Fuerst, W. L. and Barney, J. B. (1995) Information technology and sustained competitive advantage: a resource-based analysis. MIS Quarterly, 19, 487-505.

Migliarese, P. and Ferioli, C. (1997) The Organizational Relational model: proposal and results. This volume, 121-146.

Moore, J. H. and Chang, M. G. (1983) Meta-design considerations in building DSS, in Building decision support systems (ed. J. L. Bennett), AddisonWesley, Reading, MA, 173-204.

Murphy, C. (1994) Decision support systems - putting emphasis on personnel rather than technology, in Proceedings of the IFIP WG8.3 Conference on Decision support in organizational transformation (eds. B. Mayon-White, S. Ayestarán and P. Humphreys) San Sebastian, Spain, 106-120.

Ness, D. N. (1975) Interactive systems: theories of design. Paper presented at the Joint Wharton/Office of Naval Research Conference on Interactive Information and Decision Support Systems, November 4-7, Department of Decision Sciences, The Wharton School, University of Pennsylvania, Philadelphia, PA.

Nohria, N. and Ghoshal, S. (1997) The differentiated network. Jossey-Bass, San Francisco, CA.

Nunamaker, J. F., Applegate, L. M., Culnan, M. J., Fedorowicz, J., George, J. F., Gutek, B., Henderson, J. C., King, J. L., Konsynski, B. R., Star, S. L., Swanson, E. B., Valacich J. S. and Mud, R. W. (1992) Organizational decision support systems (ODSS), in Information systems and decision 
processes (eds. E. A Stohr and B. R Konsynski), IEEE Computer Society Press, Los Alamitos, CA, 137-166.

Panko, R. R. (1988) End user computing: management, applications, and technology. John Wiley \& Sons, New York.

Panko, R. R (1997a) Spreadsheet on trial: a survey of research on spreadsheet risks. Proceedings of the 29th Hawaii International Conference on Systems Sciences, 326-335. URL http://www.cba.hawaii.edu/panko/research/risks/h6trial.htm

Panko, R. (1997b) Spreadsheet research. URL http://www.cba.hawaii.edu/panko/ssr/

Ronen, B., Palley, M. A. and Lucas, H. C., Jr. (1989) Spreadsheet analysis and design. Communications of the ACM, 32 84-93.

Sage, A. P. (1991) Decision support systems engineering. John Wiley \& Sons, New York.

Scott Morton, M. S. (1971) Management decision systems: computer-based support for decision making. Graduate School of Business Administration, Harvard University, Boston, MA.

Sherr, A. L. (1993) A new approach to business processes. IBM Systems Journal, 32, 80-98.

Short, J. E. and Venkatraman, N. (1992) Beyond business process redesign: redefining Baxter's business network. Sloan Management Review, 34, 7-21.

Silver, M. S. (1991) Systems that support decision makers: description and analysis. John Wiley \& Sons, Chichester, England.

Sprague, R. H., Jr. and Carlson, E. D. (1982) Building effective decision support systems. Prentice-Hall, Englewood Cliffs, NJ.

Sprague, R. H., Jr. and Watson, H. J. (1996) Decision support for management. Prentice-Hall, Upper Saddle River, NJ.

Stabell, C. B. (1975) Design and implementation of decision support systems, some implications of a recent study, in The implementation of computer-based decision aids (ed. P. G. W. Keen), Proceedings of a Conference Sponsored by the Center for Information Systems Research, Massachusetts Institute of Technology, Cambridge, MA, April 3-5.

Stabell, C. B. (1983) A decision-oriented approach to building decision support systems, in Building decision support systems (ed. J. L. Bennett), AddisonWesley, Reading, MA, 221-260.

Tapscott, D. (1996) The digital economy: promise and peril in the age of networked intelligence. McGraw-Hill, New York.

Wernerfelt, B. (1984) A resource-based view of the firm. Strategic Management Journal, 5, 171-180.

White, D. J. (1975) Coordinating paper: the nature of decision theory, in The role and effectiveness of theories of decision in practice (eds. D. J. White and K. C. Bowen), Hodder \& Stoughton, London, 3-16.

Wyner, G. M. and Malone T. W. (1996) Cowboys or commanders: does information technology lead to decentralisation? Proceedings of the Seventeenth International Conference on Information Systems. 


\section{BIOGRAPHY}

Sven A. Carlsson is assistant professor at Department of Informatics, Lund University, Sweden. He has a Ph.D. in Informatics from the School of Economics and Management at Lund University. His research interests include the use of information technology to support both individual and group decision making, strategic information systems, organizational transformation through information technology, and knowledge management. He has been a visiting scholar at University of Arizona, Tucson, University of Southern California, and National University of Singapore. He has published in Journal of Management Information Systems, Information \& Management, Journal of Decision Systems, Scandinavian Journal of Information Systems, and international conference proceedings. 